\title{
Kilis Yağlık Zeytin Çeşidinde Döllenme Sorununun Araştırılması
}

\author{
Nurengin $\mathrm{METE}^{1 *}$, Öznur ÇETiN ${ }^{1}$ \\ ${ }^{1}$ Zeytincilik Araştırma Enstitüsü Müdürlüğü, Bornova / İzmir \\ [ORCID: http://orcid.org/0000-0003-4357-8614 (N. METE), 0000-0003-4252-0357 (Ö. ÇETIN)] \\ *Sorumlu yazar: nurengin.mete@tarim.gov.tr
}

\begin{abstract}
Öz
Birçok meyve türünde olduğu gibi zeytinde de ekonomik olarak ürün alınabilmesi için yabancı tozlanmaya intiyaç duyulmaktadır. Oysaki, ülkemizde zeytin yetiştiriciliği genellikle monokültürel olarak yapılmakta ve tozlayııı çeşit kullanımı konusunda bazı eksiklikler görülmektedir. Bu çalışmada kullanılan Kilis Yağlık çeşidi zeytinin anavatanı olarak kabul edilen Türkiye'nin Güneydoğu Anadolu Bölgesi'nde yaygın olarak yetiştirilen bir çeşittir. Bölge koşullarına uyum sağlaması ve yağ oranının yüksek olması çeşidin olumlu özelliklerindendir. Ancak; boncuklu (partenokarpik) ve kısmen gelişen meyveler nedeniyle, ağaç üzerinde irili ufaklı birçok meyvenin meydana gelmesi, çeşidin en önemli sorunu olarak görülmektedir. Çalışmada, Kilis Yağıı çeşidinde görülen bu irili ufaklı meyve oluşumlarının nedenleri ve bazı çözüm yolları araştııımıştır. Bu amaçla, uygun tozlayıcıların belirlenmesi için kendileme, serbest tozlanma ve farklı tozlayıcı uygulamaları yapılmıştır. Çalışma neticesinde bu çeşit için kendine verimliliğin ve tozlayıcıların etkinlik derecelerinin yıllar arasında değişebileceği saptanmıştır. Kendileme uygulaması oldukça az meyve tutma oranına sahip olmuş ve çeşidin kendine verimliliğinin çok düşük olduğu belirlenmiştir. Kullanılan tozlayıcıların çoğu kendilemeye göre meyve tutma oranını artıırmıştır. Ancak, tek bir tozlayıcı çeşit istenilen düzeyde bir meyve tutma oranı sağlamamıştır. Bu nedenle, Kilis Yağlık çeşidi için en az iki tozlayıcı çeşit kullanımının faydalı olacağı düşünülmektedir. Çalışmada ayrıca, çiçeklenme zamanı çiçek taç yapraklarının tam olarak açılmadığı ve meyve gelişimi esnasında sık sık tohum aborsiyonlarının oluştuğu belirlenmiştir. Birçok farklı çeşidin bulunduğu bir bahçede dahi serbest tozlanmalarda boncuklu meyve oluşumları görülmüştür. Bu durum çiçeklerin tam olarak açılmaması nedeniyle oluşan eksik tozlanmaya ve çeşidin bu konudaki genetik yatkınlığına bağlanabilir.
\end{abstract}

Anahtar Kelimeler: Zeytin, Kilis Yağlık, Boncuklu meyve, Meyve tutma oranı, Tozlanma

\section{Research on Pollination Trouble in Kilis Yaglik Olive Cultivar}

\begin{abstract}
As in several fruit species, cross-pollination is needed to be able to obtain an economical product from olive as well. However, olive cultivation is generally practiced as mono-culture in Turkey and there are some deficiencies about use of pollenizer cultivars. Kilis Yaglik olive cultivar used in this study is a variety widely cultivated in Southeastern Anatolia Region of Turkey where is accepted as the homeland of olive. Its adaptation to conditions of the region and its high oil content are favorable characteristics of the cultivar. In addition, the presence of numerous large and small fruits on the tree due to fruits that are parthenocarpic and partially developed is considered as the most critical problem of the cultivar. In the study, the causes for formation of abnormal fruits seen in Kilis Yaglik cultivar and some solutions were researched. For this purpose, self-pollination, open-pollination, and different pollenizer applications were implemented to determine optimum pollenizers for the cultivar. As a result of the study, it was determined that self-compatibility and efficiency levels of pollenizers for this cultivar might vary based on years. Self-pollination had considerably low fruit set ratio and self- compatibility of the cultivar was very low. Most of the pollenizers increased the fruit set ratio compared to self-pollination. However, not only one pollenizer cultivar provided a fruit set ratio at the desired level. Therefore, it is considered to be useful to use at least two types of pollenizers for Kilis Yaglik cultivar. It was also determined in the
\end{abstract}


study that petals of the flower did not bloom completely during florescence and seed abortions occurred frequently during fruit development. Formation of parthenocarpic fruits was seen for openpollinations even in an orchard including several different varieties. This might be attributed to incomplete pollination based on flowers, which are not able to bloom fully, as well as the genetic predisposition of the cultivar about this issue.

Key Words: Olive, Kilis Yaglik, Shot berry fruit, Fruit set, Pollination

\section{Giriş}

Zeytin ağacı Türkiye'de Ege, Akdeniz, Marmara, Güneydoğu Anadolu ve Karadeniz Bölgesi'nin uygun ekolojik koşullarında yetiştirilmektedir. Türkiye'de zeytin ağaç sayısı son 15 yıl içerisinde hızlı bir artış göstermiştir. Ancak ülke genelindeki ürün verimliliği buna paralel olarak artmamıştır. Türkiye'deki ağaç başına zeytin verimi de diğer önemli zeytinci ülkelere göre düşüktür (Mete ve ark., 2015). Bu duruma, arazi koşullarının uygun olmaması, olumsuz iklimsel faktörler, budama, sulama, hastalık ve zararlılara karşı mücadele, gübreleme gibi kültürel uygulamaların yeterince ve tekniğine uygun olarak yapılmaması etki etmektedir. Verim düşüklüğünün bir diğer nedeni de yetiştiriciliği yapılan çeşitlerin döllenme biyolojilerinin bilinmemesi veya bu konuda elde edilen bilgilerin uygulamaya aktarılmamasından kaynaklanmaktadır.

Türkiye'de zeytin yetiştiriciliği yaygın olarak monokültürel olarak yapılmakta ve tozlayıcı çeşit kullanımı konusunda bazı eksiklikler görülmektedir. Oysaki, birçok meyve türünde olduğu gibi zeytinde de ekonomik olarak ürün alınabilmesi için yabancı tozlanmaya ihtiyaç duyulmaktadır. Zeytin çeşitleri kendine verimlilik bakımından verimli, kısmen kendine verimli ve kendine verimsiz olarak gruplandırımaktadır (Kailis ve Harris, 2007). Zeytinde kendine uyuşmazlık mekanizması genetik faktörler ve çevresel koşulların etkisi altındadır (Lavee ve ark., 2002). Bu nedenle bazı araştırıcılar kendine verimli olan çeşitlerde bile uygun tozlayıcı çeşit kullanımının verime olumlu etki yaptığını belirtmişlerdir. Ferrara ve ark. (2002), tek çeşitle kurulan zeytin bahçelerindeki verim düşüklüğünün en önemli nedeninin kendine uyuşmazlık olduğunu ifade etmişlerdir. Birçok çalışmada tozlayıcı çeşit kullanımının meyve tutumunu artırdığı görülmüş ve bahçe tesisinde tozlayıcı çeşit bulundurmanın gerekliliği vurgulanmıştır (Lombardo ve ark., 2006; Farinelli ve ark., 2008; Selak ve ark., 2011; Mete ve ark., 2012; Mete ve ark., 2016).

$\mathrm{Bu}$ nedenle, çeşitlerin döllenme biyolojilerinin bilinmesi gerekliliği ortaya çıkmaktadır. Türkiye'de zeytin çeşitlerinin döllenme biyolojilerine ilişkin yapılan araştırmalarda şu ana kadar bazı çeşitlere ilişkin veriler elde edilmiştir. Güneydoğu Anadolu Bölgesi'nin önemli çeşitlerinden birisi olan Kilis Yağlık çeşidinde döllenme biyolojisi problemi olduğu uzun yıllardır bilinmektedir (Canözer, 1991; Mete ve Mısırlı, 2009). Bu amaçla yapılan çalışma kapsamında Kilis Yağlık çeşidinde görülen 
boncuklu meyve oluşumlarının nedenleri araştırılmış ve normal meyve miktarını arttırmak amacıyla farklı çeşitlerle tozlama uygulamaları gerçekleştirilmiştir.

\section{Materyal ve Metot}

Çalışma, Kemalpaşa (İzmir) Zeytin Arazi Gen Bankası'nda bulunan 40 yaşındaki Kilis Yağlık ağaçlarında 2012 ve 2014 yıllarında yürütülmüştür (38²7'49.94"K, 27²2'33.64"D). Meyve tutma oranını belirlemek amacıyla serbest tozlanma, kendileme ve yabancı tozlama uygulamaları gerçekleştirilmiştir. Bu uygulamalar için, çiçekler henüz balon döneminde iken yıllık sürgünler üzerindeki çiçekler sayılmış ve etiketlenmiştir. Etiketlenen sürgünler, serbest tozlanma için açıkta bırakılmış, kendileme ve yabancı tozlamalar için keseler yardımıyla izole edilmiştir. Yabancı tozlamalarda kullanılan çeşitlere ait çiçek tozları izolasyon keseleri yardımıyla elde edilmiş ve Kilis Yağlık çeşidindeki çiçeklerin yaklaşık \% 40-50'lik bölümü açtığında izolasyon keselerinin değiştirilmesi suretiyle birinci tozlama, çiçeklerin \% 70-80'lik bölümü açtığında ise ikinci tozlama uygulaması gerçekleştirilmiştir. Tozlanma şansını arttırmak için izolasyonda kullanılan keseler kaldırılana kadar her gün belirli aralıklarla sallanmışlardır (Mete ve Mısırlı, 2009). Tozlayıcı çeşit olarak Ayvalık, Girit, Nizip Yağlık, Gemlik, Yün Çelebi, Edincik Su, Memecik, Eğri Burun (N) ve Yağlık Çelebi çeşitleri kullanılmıştır. Meyve sayımları tam çiçeklenmeden yaklaşık 5 ay sonra gerçekleştirilmiştir. Kilis Yağlık zeytin çeşidinin kendine verimlilik durumu ve tozlayıcıların etkinliği verimlilik indeksi $(R)$ formülüne göre hesaplanmıştır. Elde edilen bulgular Çizelge 1 dikkate alınarak değerlendirilmiştir (Moutier, 2002).

$$
\begin{gathered}
R=\frac{\text { Kendileme ya da yabancı tozlamalardaki meyve tutma miktarl }}{\text { Serbest tozlamadaki meyve tutma miktarl }} \\
R=\frac{\text { Fruit set rate in self pollinations or cross pollinations }}{\text { Fruit set rate in free pollination }}
\end{gathered}
$$

Çizelge 1. Kendine uyuşma durumu ve tozlayıcıların sınıflandırılması.

\begin{tabular}{|c|c|c|c|c|c|}
\hline \multicolumn{6}{|c|}{ Kendine verimlilik (Self-fertility) } \\
\hline & 0.00 & 0.15 & & 0.30 & 1.00 \\
\hline $\mathbf{R}$ & $\begin{array}{l}\text { Kendine verimsiz } \\
\text { Self-incompatible }\end{array}$ & 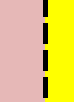 & $\begin{array}{l}\text { Kısmen kendine verimli } \\
\text { Partially self-compatible }\end{array}$ & 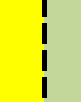 & $\begin{array}{l}\text { Kendine verimli } \\
\text { Self-compatible }\end{array}$ \\
\hline
\end{tabular}

Table 1. Classification of self-compatibility and pollenizers.

\begin{tabular}{|l|ccccc|}
\hline \multicolumn{7}{|c|}{ Karşılıklı tozlanma (Cross pollination) } \\
\hline \multirow{3}{*}{$\mathbf{R}$} & 0.00 & 0.33 & 0.66 & 1.00 \\
\cline { 2 - 6 } & & Kötü tozlayıcı & Kabul edilebilir tozlayıcı & İyi tozlayıcı \\
& & Bad pollenizer & Acceptable pollenizer & Good pollenizer \\
\hline
\end{tabular}


Zeytin ağacı, tam (erselik) ve erkek (dişi organı olmayan) çiçekler olmak üzere iki tip çiçek oluşturur. Taç yaprakların ve anterlerin dökülmesiyle dişi organ çanak yaprak içerisinde görülebilmektedir. Erkek çiçeklerde ise dişi organ aborsiyona uğradığı için çanak yaprakların içi boş kalmaktadır. Bu nedenle boncuklu meyve oranını belirlemek amacıyla, çiçeklerdeki anter ve taç yaprakların dökülmesinden sonra kendileme ve serbest tozlanma uygulamalarında tam çiçekler sayılmıştır. Boncuklu meyve oranı, tam çiçek sayısı üzerinden hesaplanmıştır.

Çalışma, tesadüf parselleri deneme desenine göre 5 tekerrürlü olarak kurulmuştur. Elde edilen verilerin istatistiksel analizi Student's $t$ gruplandırma testi uygulanarak yapılmıştır.

\section{Araştırma Bulgular ve Tartışma}

Kilis Yağlık çeşidinde gerçekleştirilen uygulamalara ilişkin bulgular ve verimlilik indeks değerleri (R) Çizelge 2'de bildirilmiştir.

Çalışmanın 1. yılında (2012) en yüksek meyve tutma oranı \% 4.45 ile serbest tozlanmada saptanmıştır. Bu uygulamayı sırasıyla Yün Çelebi (\% 1.94), Girit (\% 1.78), Memecik (\% 1.43), Ayvalık (\% 1.07), Nizip Yağlık (\% 1.06), Yağlık Çelebi (\% 1.05), Eğri Burun (Nizip) (\% 0.77), kendileme (\% 0.56) ve Edincik Su (\% 0.33) takip etmiştir. İkinci deneme yılında da (2014) en yüksek meyve tutma oranı \% 2.86 ile serbest tozlanmada elde edilmiştir. Bu uygulamayı Ayvalık (\%
2.50), Girit (\% 2.37), Gemlik (\% 2.19), Nizip Yağlık (\% 2.10), Yün Çelebi (\% 2.01), Edincik Su (\% 1.94), Memecik (\% 1.85), Eğri Burun (Nizip) (\% 1.17) ve kendileme (\% 0.84) uygulaması izlemiştir.

Kilis Yağlık zeytin çeşidinin kendine verimlilik durumu ve tozlayıcıların etkinliği bakımından önemli farklııılar ortaya çıkmıştır. Buna göre, denemenin ilk yılı kendilemedeki verimlilik indeks değeri 0.13 ile kendine verimsiz, ikinci yıl ise 0.29 ile kısmen kendine verimli olarak belirlenmiştir. Tozlayıcı çeşitlerde birinci yıl Yün Çelebi (0.44) ve Girit (0.40) kabul edilebilir tozlayıcı sınıfında yer almıştır. İkinci yıl ise Ayvalık (0.87), Girit (0.83), Gemlik (0.77), Nizip Yağlık (0.73), Yün Çelebi (0.70) ve Edincik Su (0.68) çeşitleri iyi tozlayıcı olarak saptanmışlardır. Memecik (0.65) ve Eğri Burun (Nizip) (0.41) çeşitleri ise kabul edilebilir tozlayıcılar olarak belirlenmişlerdir.

Kilis Yağlık çeşidinde daha önce yapılan bir çalışmada, çeşidin kendine verimsiz olduğu belirtilmiştir (Mete ve ark., 2012). Yine Mete (2009) bu çeşitte kullanılan tozlayıcıların etkinlik derecelerinin yıllara göre farklılık gösterdiğini ve meyve tutma oranını yeterince artırmadığını ifade etmiştir. Araştırıcı, iki yıllık veriler üzerinden yaptığı değerlendirmede Ayvalık, Edincik Su ve Memecik çeşitlerinin Kilis Yağlık için kabul edilebilir tozlayıcılar olabileceğini bildirmiş, ancak yeni çalışmalarla konunun daha ayrıntılı olarak incelenmesinin faydalı olacağını belirtmiştir. Bu çalışmada da benzer sonuçlara ulaşılmıştır. Nitekim gerek kendine verimlilik durumu gerekse tozlayıcıların etkinliği yıllar arasında 
farklılık göstermiştir. Zeytinde tozlanma ve döllenmenin sıcaklık, yağmur ve rüzgarın durumuna göre değişim gösterdiği bilinmektedir (Fabbri ve ark., 2004). Farinelli ve ark. (2006), zeytin çeşitlerinin kendine uyuşma durumunun yıllar arasında farklılık göstermesini çeşit, ışıklanma, sıcaklık, çiçek tomurcuğu oluşumu ve çiçeklenme esnasındaki iklim faktörlerinden sonucuna varmışlardır. Bu bilgiler ışığında Kilis Yağlık çeşidi için tozlayıcı seçiminde birden fazla çeşidin kullanılmasının daha uygun olacağı düşünülmektedir. Geçmiş yıllardaki araştırmalar ve mevcut çalışma dikkate alındığında Ayvalık, Girit, Nizip Yağlık, Gemlik, Yün Çelebi, Memecik ve Edincik Su çeşitlerinden en az ikisinin tozlayıcı olarak kullanılması faydalı olacaktır.

Çizelge 2. Kilis Yağıı çeşidine ait meyve tutum ve verimlilik indeks (R) değerleri

Table 2. Fruit set and fertility index $(R)$ values on the Kilis Yaglik olive cultivar

\begin{tabular}{|c|c|c|c|c|c|}
\hline \multirow{2}{*}{\multicolumn{2}{|c|}{$\begin{array}{c}\text { Tozlanma şekli } \\
\text { Type of pollination }\end{array}$}} & $\begin{array}{l}\text { Meyve tutma oranı (\%)* } \\
\text { Fruit set }\end{array}$ & $\mathbf{R}$ & $\begin{array}{l}\text { Meyve tutma oranı (\%) * } \\
\text { Fruit set }\end{array}$ & $\mathbf{R}$ \\
\hline & & \multicolumn{2}{|l|}{$1^{\text {st }}$ Year (2012) } & \multicolumn{2}{|l|}{$2^{\text {nd }}$ Year (2014) } \\
\hline \multicolumn{2}{|c|}{$\begin{array}{l}\text { Serbest tozlanma } \\
\text { Open pollination }\end{array}$} & $4.45 \mathrm{a}$ & - & $2.86 \mathrm{a}$ & - \\
\hline \multicolumn{2}{|c|}{$\begin{array}{l}\text { Kendileme } \\
\text { Self pollination }\end{array}$} & $0.56 \mathrm{~cd}$ & 0.13 & $0.84 \mathrm{~d}$ & 0.29 \\
\hline \multirow{9}{*}{ 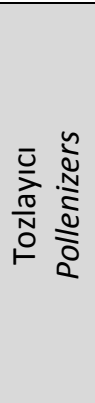 } & Yün Çelebi & $1.94 \mathrm{~b}$ & 0.44 & $2.01 \mathrm{abc}$ & 0.70 \\
\hline & Girit & $1.78 \mathrm{~b}$ & 0.40 & $2.37 \mathrm{ab}$ & 0.83 \\
\hline & Memecik & $1.43 \mathrm{bc}$ & 0.32 & $1.85 \mathrm{bcd}$ & 0.65 \\
\hline & Ayvalık & $1.07 \mathrm{bcd}$ & 0.24 & $2.50 a b$ & 0.87 \\
\hline & Nizip Yağlık & $1.06 \mathrm{bcd}$ & 0.24 & $2.10 \mathrm{abc}$ & 0.73 \\
\hline & Yağlık Çelebi & $1.05 \mathrm{bcd}$ & 0.24 & - & - \\
\hline & Gemlik & - & - & $2.19 a b$ & 0.77 \\
\hline & Eğri Burun $(\mathrm{N})$ & $0.77 \mathrm{~cd}$ & 0.17 & $1.17 \mathrm{~cd}$ & 0.41 \\
\hline & Edincik Su & $0.33 \mathrm{~d}$ & 0.07 & $1.94 \mathrm{abc}$ & 0.68 \\
\hline
\end{tabular}

${ }^{*}$ Ortalamalar Student's t testine ( $\left.p<0.05\right)$ göre gruplandırılmıstıtı. $R$ : Verimlilik indeks değeri.

${ }^{*}$ Means grouped by Student's $t$ test $(p<0,05$. R: Fertility index value.

Zeytinde boncuklu meyve oluşumunun tozlanma eksikliğinden kaynaklandığı uzun yıllardır bilinmektedir (Cuevas ve ark., 2001). Lavee (1998)'de ovaryumun anormal gelişimi ile zeytinde bu tür meyve oluşumlarının görülebileceğini ifade etmiştir. Kilis Yağlık çeşidinde bu duruma ilişkin çiçeklenme döneminde bazı gözlemler yapılmıştır. Buna göre bazı çiçeklerde taç yaprakların tam olarak açılmadığı (Şekil 1), birçok çiçekte de anterlerin patlamadan kararıp döküldüğü gözlemlenmiştir. Tam çiçeklenmeden yaklaşık 10 gün sonra yapılan gözlemlerde ise bazı çiçeklerde dişi organın kısmen gelişerek büyüdüğü ve tam olarak açılmayan taç yapraklar ile anterleri düşürdüğü saptanmıştır (Şekil 2). Bu durumun, dişi organın tozlanma olasılığını azalttığı ve boncuklu meyve oluşumunu tetiklediği düşünülmektedir. Kilis Yağlık çeşidinde benzer bulgulara daha öncede ulaşılmıştır (Mete ve Mısırlı, 2009). 


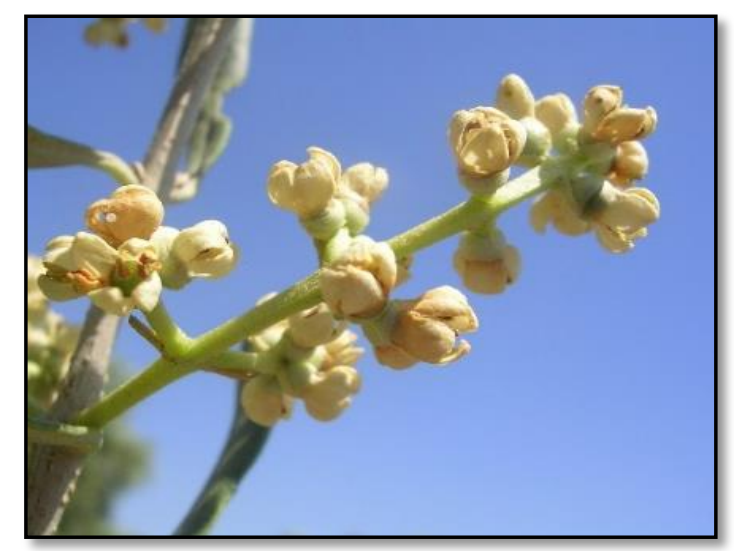

Şekil 1. Çiçeklenme durumu

Figure 1. Flowering status

Meyvelerde yapılan incelemelerde, somaklar üzerinde çok küçük kümeler halinde bulunan meyveler, kısmen gelişmiş küçük meyveler ve daha irileşmiş normal meyveler görülmüştür (Şekil 3).

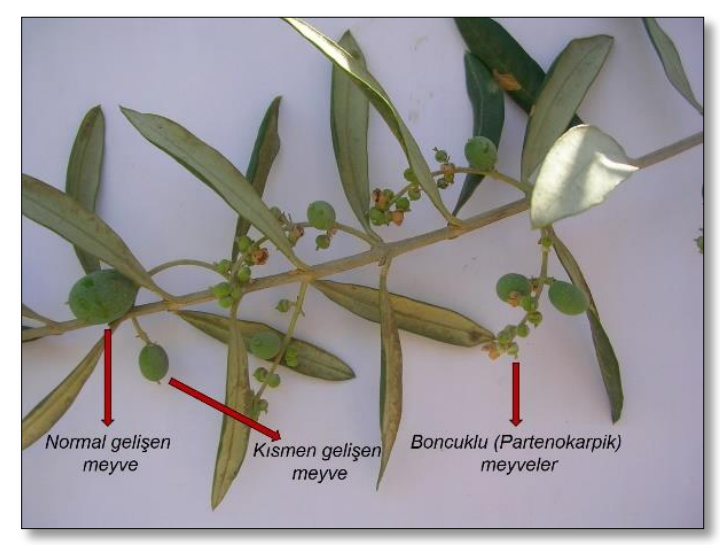

Şekil 3. Kilis Yağlık çeşidinde görülen meyve gelişimleri

Figure 3. Fruit development in Kilis Yaglik cultivar

Zeytinde embriyo aborsiyonunun sık meydana geldiği ve aborsiyonun meyve gelişiminin farklı devrelerinde ortaya çıkabileceği ifade edilmektedir. Bu tip meyvelerin büyüklüğünün de aborsiyonunun meydana geldiği zamana bağlı olarak değiştiği belirtilmiştir (Lavee,

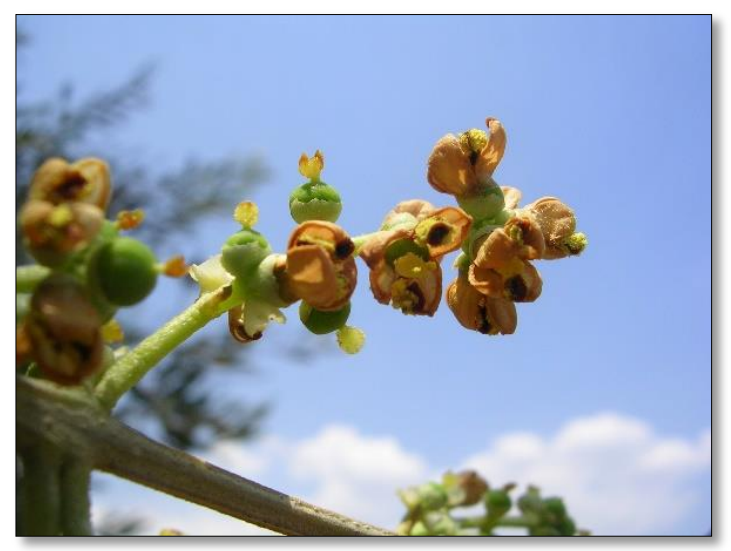

Şekil 2. Kısmen açılan çiçeklerde dişi organın gelişimi

Figure 2. Pistil development in partially opened flowers

1998; Farinelli ve ark., 2008). Ayrıca, döllenmeyi sağlayan çiçek tozu kaynağına bağlı olarak da tohum aborsiyonu oranının değişebildiği bildirilmektedir (Cuevas ve Oller, 2002; Farinelli ve ark., 2008; Mete ve Mısırlı, 2009). Kilis Yağlık çeşidinde de benzer bulgulara ulaşılmıştır.

Nitekim, kısmen gelişen meyvelerde farklı zamanlarda yapılan incelemelerde, endokarp içerisindeki tohumların başlangıçta gelişme gösterdiği ancak, ilerleyen dönemde canlılığını kaybederek karardığı görülmüştür. Buna göre, meyve gelişiminin farklı zamanlarında meydana gelebilen tohum aborsiyonlarının Kilis Yağlık çeşidindeki irili ufaklı meyve oluşumlarının nedenlerinden birisi olabileceği düşünülmektedir. Şekil 4'de canlı tohuma sahip olan ve tohum aborsiyonuna uğramış meyveler birlikte görülmektedir. 


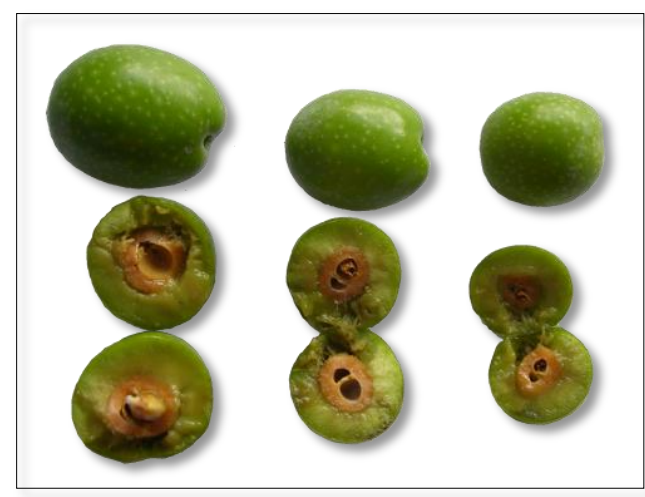

Şekil 4. Tohum aborsiyonları ve meyve gelişimi Figure 4. Seed abortions and fruit development

Çalışmada anormal meyve gelişimlerinin kendileme ve serbest tozlanma uygulamalarındaki oranları da araştırılmıştır (Şekil 5). Tam çiçekler üzerinden yapılan bu değerlendirmede 1 . yıl kendileme uygulamasında \% 40.35, 2. yıl ise \% 30.01 boncuklu meyve saptanmıştır. Serbest tozlanmada bu oranlar ilk yıl \% 3.81, ikinci yıl \% 8.60 olarak belirlenmiştir. Uygulamaların tam çiçek oranları ilk yıl kendilemede \% 19.87, serbest tozlamalarda \% 27.52 olmuştur. İkinci yıl ise kendilemede \% 21.93 , serbest tozlamalarda ise \% 28.34 olarak saptanmıştır. Rallo ve ark. (1981), zeytin ağaçlarında tam çiçek oranındaki farklılığın toplam üründe çok önemli bir etki oluşturmadığını iddia etmişlerdir. Guerin ve Sedgley (2007), bu durumun ağaç üzerinde oluşan çiçeklerden çok az bir kısmının meyveye dönüşmesi nedeniyle olabileceğini açıklamışlardır. Bununla birlikte bazı durumlarda bol miktarda erkek çiçek meydana getiren ağaçlarda üründe bir azalmanın meydana gelebileceği de bildirilmiştir (Griggs ve ark., 1975; Martins ve ark., 2006). Ülkemizde yapılan bir çalışmada da bazı yıllar Eşek Zeytini (Ödemiş) çeşidinde tam çiçek oranının oldukça düşük düzeyde olduğu ve bu durumun verimde bir azalmaya neden olduğu belirtilmiştir (Mete ve Misırlı, 2009). Zeytin ağaçlarında normal bir çiçeklenmenin olduğu yılda \%2-4 arasında meyve tutma oranının verimlilik açısından yeterli olduğu ifade edilmiştir (Bartolucci ve Dhakal, 1999). Bu nedenle mevcut çalışmada tespit edilen tam çiçek oranlarının verimlilik açısından yeterli olduğu düşünülmektedir. Serbest tozlanma ve kendilemelerden elde edilen boncuklu meyve miktarı dikkate alındığında tozlayıcı kaynağının bu duruma etki ettiği görülmektedir. Ancak, birçok farklı çeşidin bulunduğu bir bahçede dahi serbest tozlanmalarda boncuklu meyve oluşumlarının meydana gelmesi çiçeklerin tam olarak açılmamasına bağı olarak eksik tozlanmadan ve çeşidin bu konudaki genetik yatkınlığına bağlanabilir. Nitekim, zeytinde boncuklu meyve oluşumunun tozlanma eksikliğinden kaynaklandığı belirtilmekle birlikte bu durumun her zaman geçerli olmayabileceği de ifade edilmiştir (Ayerza ve Coates, 2004). Lavee (1998), boncuklu meyvelerin genellikle somak üzerinde normal bir meyve gelişimi olduğunda döküleceğini ve tozlayıcı çeşit kullanımının bu durumu azaltmada etkili olacağını belirtmiştir. Ancak araştırıcı, Cucco ve Sevillano gibi bazı çeşitlerin somak üzerinde normal meyvelerle birlikte, boncuklu meyve üretme konusunda genetik yatkınlık gösterdiğini ifade etmiştir. Benzer bulgulara Kilis Yağlık çeşidinde de rastlanmıştır. 


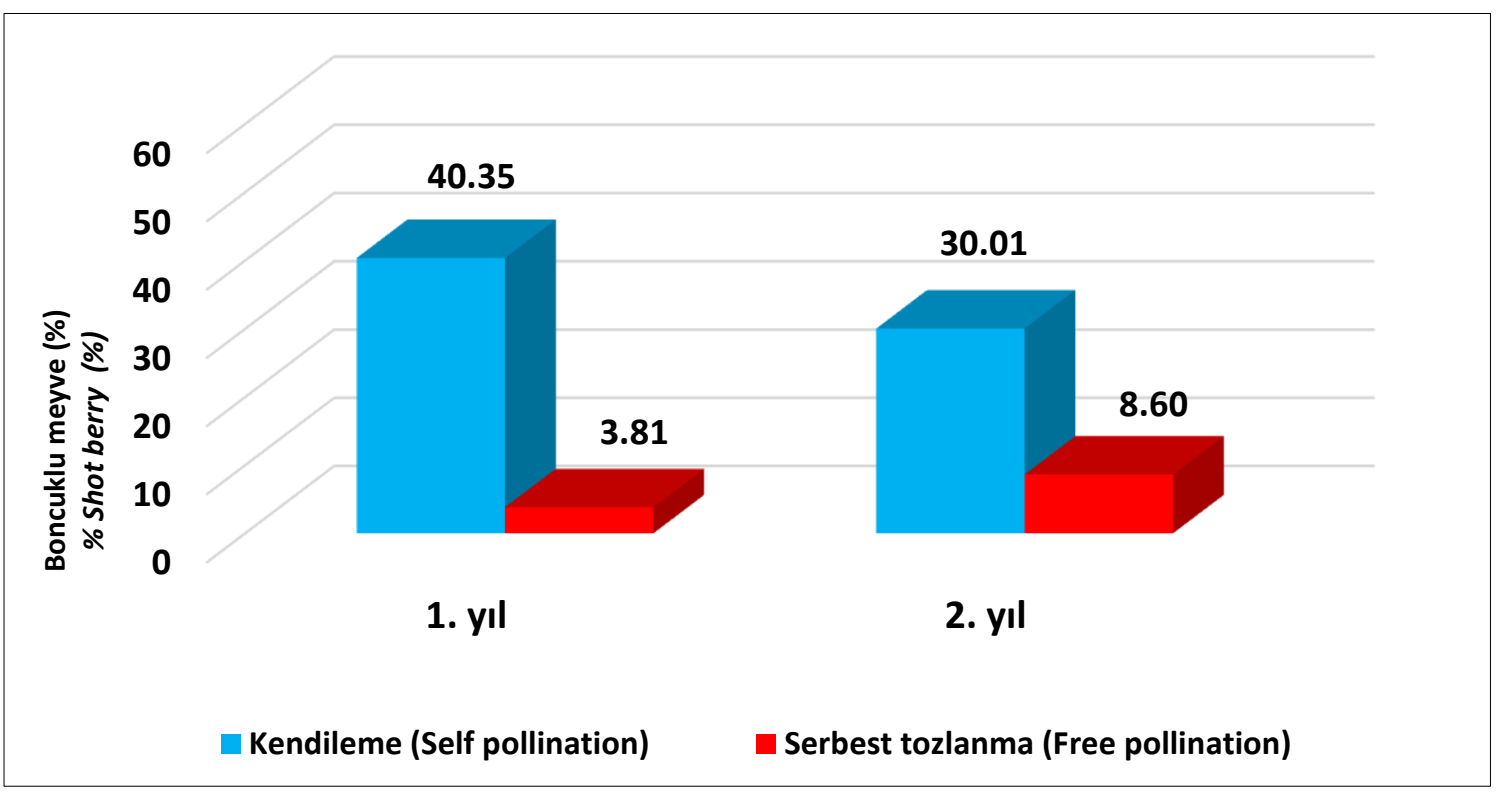

Şekil 5. Kilis Yağlık çeşidinde kendileme ve serbest tozlanma uygulamalarında boncuklu meyve oranları (\%)

Figure 5. Shot berry fruit rates (\%) in open - self pollination applications on the Kilis Yaglik cultivar

\section{Sonuçlar}

Kilis Yağlık çeşidi irili ufaklı meyve oluşumları ve bol miktarda boncuklu meyve meydana getirmesi nedeniyle bu konuda dikkat çeken bir çeşittir. Çalışmadan elde edilen bulgular neticesinde, bu çeşitte çiçeklenme zamanı bazı çiçek taç yapraklarının tam olarak açılmaması ve meyve gelişimi esnasında meydana gelen tohum aborsiyonlarının çeşitte oluşan irili ufaklı meyve oluşumlarına sebep olabileceği sonucuna varılmıştır. Ayrıca, bu çeşit için kendine verimliliğin ve tozlayıcıların etkinlik derecelerininin yıllar arasında değişebileceği saptanmıştır.

Araştırmada, en düşük meyve tutma oranları büyük ölçüde kendileme uygulamasında saptanmış ve Kilis Yağlık çeşidinin kendine verimliliğinin çok düşük olduğu belirlenmiştir. Bu nedenle, bahçe tesisinde verim düşüklüğünü ve anormal meyve gelişimini azaltmak için tozlayıcı çeşit kullanımının faydalı olacağı düşünülmektedir.

\section{Kaynaklar}

Ayerza, R., Coates, W., 2004. Supplemental Pollination - Increasing Olive (Olea europaea) Yields in Hot, Arid Environments, Exp. Agric. 40:481-491.

Bartolucci, P., Dhakal, B.R., 1999. Prospects for Olive Growing in Nepal. Department of Agriculture, Fruit Development Division Olive Production Development Project, $\mathrm{TCP} / \mathrm{NEP} / 6713$ \& Food and Agriculture Organization of the United Nations, $62 \mathrm{pp}$.

Canözer, Ö., 1991. Standard Zeytin Çeşitleri Kataloğu. Tarım ve Köyişleri Bakanlığı Yayınları. No: 334, Seri :16.

Cuevas, J., Diaz-Hermoso, A. J., Gali'an D, Hueso J. J., Pinillos, V., Prieto, M., Sola, D., Polito, V. S., 2001. Response to Cross Pollination and Choice of Pollinators for the Olive Cultivars (Olea europaea L.) 'Manzanilla de Sevilla', 'Hojiblanca', and 'Picual'. Olivae 85: 26-32.

Cuevas, J., Oller, R., 2002. Olives Set and its Impact on Seed and Fruit Weight. Acta Horticulturae, 586: 485-488. 
Fabbri, A., Bartolini, G., Lambardi, M., Kailis, S, 2004. Olive Propagation Manual. CSIRO Publ., Australia, pp: 130.

Farinelli, D., Boco, M., Tombesi, A., 2006. Results of Four Years of Observations on Self Sterility Behaviour of Several Olive Cultivars and Significance of Cross Pollination. Proceedings Second International Seminar Olivebioteq 2006, Mazara del Vallo (TP), 5-10 November, pp. 275-282.

Farinelli, D., Tombesi, A., Hassani, D., 2008. SelfSterility and Cross-Pollination Responses of Nine Olive Cultivars in Central Italy. Acta Horticulturae, 791: 127-136.

Ferrara, E., Papa, G., Lamparelli, F., 2002. Evaluation of the Olive Germplasm in the Apulia Region: Biological and Technological Characteristics. Acta Horticulturae, 586: 159-162.

Griggs, W.H., Hartmann, H.T., Bradley, M.V., Iwakiri, B.T., Whisler, J.E., 1975. Olive Pollination in California. Bulletin 869. University of California, Davies, CA.

Guerin, J., Sedgley, M., 2007. Cross-Pollination in Olive Cultivars. RIRDC Puclication No 07/169. RIRDC Project No UA-65A.

Kailis, S., Harris, D., 2007. Producing Table Olives. SBN 9780643092037. P:53.

Lavee, S., 1998. Zeytinin Biyolojisi ve Fizyolojisi. Dünya Zeytin Ansiklopedisi Uluslararası Zeytinyağı Konseyi. ISBN: 84-01-61944-0. İspanya, s: $61-110$.

Lavee, S., Taryan, J., Levin, J., Haksal, A., 2002. The Significance of Cross-Pollination for Various Olive Cultivars under Irrigated Intensive Growing Conditions. Olivae, 91: 25-36.

Lombardo, N., Alessandrino, M., Godino, G., Madeo, A., 2006. Comparative
Observations Regardding the Floral Biology of 150 Italian Olive (Olea europae L.) cultivars. Adv. Hort. Sci. 20: 247-255.

Martins, P.C., Cordeiro, A.M., Rapoport, H.F., 2006. Flower Quality in Orchards of Olive, Olea Europaea L., cv. Morisca. Adv Hortic Sci 20:262-266.

Mete, N., Mısırlı, A., 2009. Bazı Zeytin Çeşitlerinin Döllenme Biyolojisi Üzerinde Araştırmalar. Ege Üniversitesi Fen Bilimleri Enstitüsü. Yüksek Lisans Tezi.

Mete, N., Mısırlı, A., Çetin, Ö., 2012. Determining the Biology of Fertilization and Pollinators in Some Olive Cultivars. Proceedings of the 4th International Conference on "Olive Culture and Biotechnology of Olive Tree Products". P: 69-74.

Mete, N., Şahin, M., Çetin, Ö., 2015. Zeytinde Döllenme Biyolojisi. Zeytin Bilimi, 13095889. Cilt 5. Sayı 1. S:27.

Mete, N., Şahin, M., Çetin, Ö., 2016. Determination of Self-Fertility of the 'Hayat' Olive Cultivar Obtained by Hybridization Breeding. Journal of Tekirdag Agricultural Faculty, 13(3): 60-64.

Moutier, N., 2002. Self-Fertility and InterCompatibilities of Sixteen Olive Varieties. Acta Horticulturae, 586: 209-212.

Rallo, L., Martin, G.C., Lavee, S., 1981. Relationship between Abnormal Embryo Sac Development and Fruitfulness in Olive. Journal of the American Society for Horticultural Science 106: 813-817.

Selak, G.V., Perica, S., Goreta Ban, S., Radunic, M., 2011. Reproductive Success after SelfPollination and Cross-Pollination of Olive Cultivars in Croatia. Hortscience, 46(2): 186-191. 